\title{
Do We Use Artificial Light Appropriately?
}

\author{
Heon-Jeong Lee, Editor-in-Chief \\ Department of Psychiatry, Korea University College of Medicine, Seoul, Republic of Korea
}

It is clear that the invention of artificial light has brought great benefits to mankind. However, are we really using artificial light appropriately? Artificial light's great contribution is to illuminate dark places and enable us to work without inconvenience in places with limited natural light or at night.

In recent years, however, there is increasing evidence on the adverse effects of artificial light at night (LAN) on the nature and on humans. Several studies have reported that inappropriate artificial LAN influences sleep and emotional disturbance in humans. ${ }^{1}$ The dysregulation of the circadian rhythm caused by artificial LAN not only causes sleep problems, but it also has a great influence on mood disorders such as depression, bipolar disorder, and human mood dysregulation. ${ }^{2}$ Excessive artificial LAN and inadequate exposure to natural light during daytime have been found to cause mood disturbances, which, on the contrary, means that appropriate use of artificial light can be used to prevent and treat sleep and mood disorders.

The therapeutic effects of bright light on depression, insomnia, and jet lag are already well known, and Dr. Kripke's website provides useful information for the treatment of such conditions using bright light. ${ }^{3}$ However, we still do not know about the correct application of bright light treatment. Although a previous study reported that manic switches were induced by morning bright light therapy in women with bipolar depression, ${ }^{4}$ a recent 6 -week randomized double-blind placebocontrolled trial revealed that mid-day bright light therapy was effective in improving depressive symptoms and that it did not increase the risk of manic switch in participants experiencing depressive episodes of bipolar disorders. ${ }^{5}$ It is clear that this study has made significant progress regarding the use of bright light treatment. However, the questions that need further investigation include the use of this treatment to prevent recurrence, the biological mechanisms and potential predictors of treatment effectiveness, and the differences in treatment methods depending on the type of mood disorder.

This issue of the journal includes a study protocol on the use of morning or mid-day bright light therapy for non-seasonal

(c) This is an Open Access article distributed under the terms of the Creative Commons Attribution Non-Commercial License (https://creativecommons.org/licenses/bync/4.0) which permits unrestricted non-commercial use, distribution, and reproduction in any medium, provided the original work is properly cited. bipolar depressive episodes. ${ }^{6}$ This study protocol is of interest as a study design that validates the effects of morning or midday treatment for non-seasonal bipolar depression. The successful implementation of this study will provide useful information on the treatment of mood disorders, especially bipolar depression. Globalization and the increasing use of individual LED emitting devices will add to the problems occurring due to the disturbance of the light-dark cycle in humans. Therefore, more research needs to focus on the mental and physical health of individuals travelling to places in different time zones and on the effects of the inappropriate use of LAN.

\section{Acknowledgments}

This study was supported by the Korea Health 21 R\&D Project, funded by the Ministry of Health \& Welfare, Republic of Korea (HM14C2606) and by the National Research Foundation of Korea (2016M3C7A1904345 and 2017M3A9F1031220).

\section{REFERENCES}

1. Cho CH, Moon JH, Yoon HK, Kang SG, Geum D, Son GH, et al. Molecular circadian rhythm shift due to bright light exposure before bedtime is related to subthreshold bipolarity. Sci Rep 2016;6:31846.

2. Lee HJ. Is the circadian rhythm dysregulation a core pathogenetic mechanism of bipolar disorder? J Korean Neuropsychiatr Assoc 2018; 57:276-286.

3. Kripke DF. Brighten your life: how bright light therapy helps with low mood, sleep problems and jet lag. Available at: http://www.brightenyourlife.info. Accessed November 30, 2018.

4. Sit DK, Wisner KL, Hanusa BH, Stull S, Terman M. Light therapy for bipolar disorder: a case series in women. Bipolar Disord 2007;9:918927.

5. Sit DK, McGowan J, Wiltrout C, Diler RS, Dills JJ, Luther J, et al. Adjunctive bright light therapy for bipolar depression: a randomized double-blind placebo-controlled trial. Am J Psychiatry 2018;175:131-139.

6. Geoffroy PA, Abbassi EMBE, Maruani J, Etain B, Lejoyeux M, Amad A, et al. Bright light therapy in the morning or at mid-day in the treatment of non-seasonal bipolar depressive episodes (LuBi): study protocol for a dose research phase I/II trial. Psychiatry Investig 2018;15: 1188-1202. 